\title{
Diet, lifestyle and chronic widespread pain: Results from the 1958 British Birth Cohort Study
}

\author{
Elizabeth G VanDenKerkhof RN DrPH${ }^{1}$, Helen M Macdonald $\mathrm{PhD}^{2}$, Gareth $\mathrm{T}$ Jones $\mathrm{PhD}^{3}$, \\ Chris Power $\mathrm{PhD}^{4}$, Gary J Macfarlane PhD MD(Hons) $)^{3,5}$
}

EG VanDenKerkhof, HM Macdonald, GT Jones, C Power, GJ Macfarlane. Diet, lifestyle and chronic widespread pain: Results from the 1958 British Birth Cohort Study. Pain Res Manage 2011;16(2):87-92.

OBJECTIVES: To examine the relationship between diet and lifestyle, and chronic widespread pain (CWP). If persons with CWP have dietary and lifestyle habits consistent with an increased risk of cancer or cardiovascular disease, it may partially explain evidence in the literature suggesting an association between CWP and these diseases.

METHODS: The 1958 British Birth Cohort Study comprises individuals born in England, Scotland and Wales in the United Kingdom during one week in March 1958. At 45 years of age, pain was recorded using a self-completion questionnaire. CWP was classified using the American College of Rheumatology definition for fibromyalgia. Data were collected on diet and lifestyle at 33 and 42 years of age.

RESULTS: A total of 8572 participants provided pain data at 45 years of age, of whom $12 \%$ reported CWP. Women with CWP, compared with those without, reported an unhealthy diet (ie, fruit/vegetable consumption less than once per week [OR 2.0; 95\% CI 1.3 to 3.1], and fatty food [OR 1.7; 95\% CI 1.1 to 2.7] and chips (french fries) [OR 1.5; 95\% CI 1.0 to 2.4] at least once per day) that may have predisposed them to other chronic diseases such as cancer and cardiovascular disease. Women with CWP were also more likely to be unemployed (adjusted OR 1.4; 95\% CI 1.1 to 1.8 ), to have had high physical exertion at work (adjusted OR 1.6; 95\% CI 1.2 to 2.2 ) and elevated body mass index (overweight - adjusted OR $1.5,95 \%$ CI 1.2 to 1.9 ; obese - adjusted OR $1.8,95 \%$ CI 1.3 to 2.5 ). Similar relationships between lifestyle (but not diet) and the risk of CWP were identified in men.

CONCLUSIONS: The findings for smoking, body mass index and (for women) diet offer support for the hypothesis that lifestyle factors may partially explain the association between CWP and cancer or cardiovascular disease. Prospective studies are necessary to confirm this relationship.

Key Words: 1958 British Birth Cohort; Cancer; Cardiovascular disease; Chronic widespread pain; Diet; Lifestyle; Physical activity

\section{Le régime alimentaire, le mode de vie et la douleur généralisée chronique : les résultats de l'étude de cohorte britanno-colombienne de 1958}

OBJECTIFS : Examiner la relation entre le régime alimentaire, le mode
de vie et la douleur généralisée chronique (DGC). Chez les personnes
ayant des DGC ont des habitudes diététiques et liées au mode de vie
compatibles avec un risque accru de cancer ou de maladie cardiovasculaire,
ces comportements peuvent expliquer partiellement les données probantes
des publications laissant supposer une association entre la DGC et ces
maladies. MÉTHODOLOGIE : L'étude de cohorte britanno-colombienne de 1958 se compose de personnes nées en Angleterre, en Écosse et au Pays de Galles au Royaume-Uni suivies pendant une semaine en mars 1958. Les chercheurs ont enregistré la douleur à 45 ans, au moyen d'un questionnaire autoadministré. Ils ont classé la DGC selon la définition de fibromyalgie de l'American College of Rheumatology. Ils ont colligé les données sur le régime alimentaire et le mode de vie à 33 et 42 ans.

RÉSULTATS : Au total, 8572 participants ont fourni des données sur la douleur à 45 ans, et $12 \%$ ont déclaré une DGC. Les femmes ayant une DGC, par rapport celles qui n'en ressentaient pas, déclaraient un régime non équilibré (c'est-à-dire une consommation de fruits et de légumes moins d'une fois par semaine [RRR 2,0; 95 \% IC 1,3 à 3,1], d'aliments gras [RRR 1,$7 ; 95 \%$ IC 1,1 à 2,7] et de croustilles [patates frites] [RRR 1,5; $95 \%$ IC $1,0$ à 2,4$]$ au moins une fois par jour) qui peut les avoir prédisposées à d'autres maladies chroniques comme le cancer et une maladie cardiovasculaire. Les femmes ayant une DGC étaient également plus susceptibles d'être sans emploi (RRR rajusté 1,4; $95 \%$ IC 1,1 à 1,8), d'avoir fait beaucoup d'effort physique au travail (RRR rajusté 1,6; 95 \% IC 1,2 à 2,2 ) et d'avoir un indice de masse corporelle élevée (embonpoint - RRR rajusté $1,5,95 \%$ IC 1,2 à 1,9 ; obésité - RRR rajusté $1,8,95 \%$ IC 1,3 à 2,5). Les chercheurs ont constaté des relations similaires entre le mode de vie (mais pas le régime alimentaire) et le risque de DGC chez les hommes.

CONCLUSION : Les observations relatives au tabagisme, à l'indice de masse corporelle et au régime alimentaire (pour les femmes) appuient l'hypothèse que des facteurs liés au mode de vie peuvent expliquer partiellement l'association entre la DGC et le cancer ou la maladie cardiovasculaire. Des études prospectives s'imposent pour confirmer ce lien.

such as a sedentary lifestyle and smoking, which have been linked with CWP $(9,10)$. In addition, evidence for a link between diet and chronic pain is beginning to emerge. Dietary markers, including low fruit and vegetable consumption, have been identified for inflammatory arthritis (11). Low levels of 25-hydroxyvitamin D have been associated with the report of musculoskeletal pain (12) and, specifically in South Asian populations, related to reports of CWP $(13,14)$. A dose-response relationship between body mass index (BMI) and both pain intensity and number of pain sites has also been reported (15).
$T^{1}$ here is a paucity of information on the relationship between diet arding whether people with pain hecific past dietary the onset or persistence of pain. However, evidence is emerging that individuals with CWP may experience an increased risk of morbidity and early mortality from cardiovascular disease (CVD) and certain cancers (1-3). The cancers and CVD identified in studies of CWP are also associated with certain diet and lifestyle characteristics (4-8)

${ }^{1}$ Department of Anesthesiology 83 Perioperative Medicine and School of Nursing, Queen's University, Kingston, Ontario; ${ }^{2}$ Osteoporosis Research Unit, School of Medicine; ${ }^{3}$ Aberdeen Pain Research Collaboration (Epidemiology Group), University of Aberdeen, Aberdeen; ${ }^{4}$ Centre for

Paediatric Epidemiology and Biostatistics, Institute of Child Health, University College London, London; 5 School of Medicine and Dentistry, University of Aberdeen, Aberdeen, United Kingdom

Correspondence: Prof Elizabeth G VanDenKerkhof, Department of Anesthesiology Eु Perioperative Medicine, Queen's University, Kingston General Hospital, 76 Stuart Street, Kingston, Ontario K7L 2V7. Telephone 613-549-6666 ext 3964, fax 613-548-1375, e-mail ev5@queensu.ca 
Also, both poor diet and CWP have been associated with being overweight (16).

There are several possible explanations for the increased risk of cancer and CVD among persons with CWP. The purpose of the present study was to examine the relationship between CWP and specific dietary and lifestyle factors known to be risk factors for cancer and CVD. If persons with CWP have dietary and lifestyle habits consistent with an increased risk of cancer and CVD, it may partially explain the apparent association between CWP and cancer or CVD.

\section{METHODS}

\section{Subjects}

Using a nested case-control design, data from the 1958 British Birth Cohort Study (also known as the National Child Development Study) were used to examine the relationship between widespread pain and past diet and lifestyle. The 1958 British Birth Cohort Study (detailed methods have been reported previously [17]) is a large, ongoing, prospective cohort study of all children born in England, Scotland and Wales in the United Kingdom during one week of March 1958. Approximately 17,000 participants were recruited at birth and were subsequently followed up at ages seven, 11, 16, 23, 33, 42 and 45 years. At each follow-up, a variety of data were collected including information on socioeconomic status, health and development, and familial and education factors. At 33 and 42 years of age, diet, lifestyle and occupational factors were also collected. At 45 years of age, a biomedical survey collected information on health-related factors including the presence of pain (17). The sample for the current study was 8572 individuals who responded to a self-completed questionnaire at 45 years of age, sent in advance of a nurse interview.

At 45 years of age, participants were asked, "During the past month, have you had any ache or pain which has lasted for one day or longer?" and were directed not to include pain that occurred during menstrual periods or during the course of a feverish illness. Those who answered positively were asked to indicate the location(s) of their pain on a diagram of a four-view blank body manikin. In addition, participants were asked to state whether they had been aware of the pain for more than three months. CWP case definition was based on the American College of Rheumatology classification criteria for fibromyalgia (18). For this definition, pain must be present for three months or longer, both above and below the waist, on both the left and right sides of the body, and in the axial skeleton (upper spine, lower back or sternum). Participants who reported chronic pain but did not meet the requirements of this definition were classified as having regional pain. All remaining participants were classified as having no pain (ie, controls).

At 33 years of age, participants provided information on exercise frequency (physical activity), employment status, physical effort at work and smoking habits. Participants were provided with a list of sports and activities and asked about the frequency at which they performed them. The response categories were high (four to seven days per week), medium (two to three days per week), low (one day per week) or rarely (three days per month or less) (19). Paid employment was classified as yes (full time, part time or self employed) or no (unemployed, in education, sick, disabled, at home or other). Physical exertion at work was categorized as no (some, a little, no, or not working) or yes (a lot). Smoking was categorized as never, past or current. Height and weight, measured by a nurse in the participant's home, was used to calculate BMI in $\mathrm{kg} / \mathrm{m}^{2}$. Only 136 participants $(1.8 \%)$ had a BMI of less than $18.5 \mathrm{~kg} / \mathrm{m}^{2}$ (underweight). A sensitivity analysis excluding these individuals did not alter the final results; therefore, they were left in the analysis. BMI was classified as normal weight (less than $\left.25 \mathrm{~kg} / \mathrm{m}^{2}\right)$, overweight $\left(25 \mathrm{~kg} / \mathrm{m}^{2}\right.$ to less than $\left.30 \mathrm{~kg} / \mathrm{m}^{2}\right)$ and obese $\left(30 \mathrm{~kg} / \mathrm{m}^{2}\right.$ or greater $)$.

Also at 33 years of age, participants were asked to classify how often they consumed fresh fruit and vegetables, fatty foods, chips (french fries) or alcohol. Six possible response categories were provided - more than once per day, once per day, three to six days per week, one or two days per week, less than once per week and never. In accordance with previously published reports on this cohort (19), fruit and vegetable consumption frequency was classified as high (more than once per day), medium (once per day), low (one to six days per week) or rarely (less than one day per week). Fatty food and chips consumption frequency was classified as high (one or more times per day), medium (one or two days per week), low (less than one day per week) or rarely (occasionally or never). Alcohol consumption frequency was classified as high (four times or more per week), medium (two to three times per week), low (two to four times per month), rarely (one time or less per month) or never (not in the last 12 months).

\section{Potential confounding factors or effect modifiers}

Marital status at 33 years of age was classified as single (never married), first marriage, or other (married more than once, legally separated, divorced or widowed). The United Kingdom Register General's six categories of occupational class were used to measure social class at 33 years of age. These include professional (I), managerial-technical (II), skilled nonmanual (IIInm), skilled manual (IIIm), partly skilled (IV), unskilled (V) and unknown/unstated. There is reason to believe that the relationships between CWP and diet and lifestyle factors may differ according to sex. Women generally report higher levels of CWP $(20,21)$ and different dietary and lifestyle characteristics than men (22). Hence, a decision to conduct an analysis stratified according to sex was made a priori.

\section{Data analysis}

All analyses were performed using SPSS version 15.0 (IBM Corp, USA) for Windows (Microsoft Corp, USA. The relationship between both case groups (CWP) and controls (no pain) with respect to previous diet and lifestyle factors was assessed using logistic regression; thus, the associations are expressed as ORs with 95\% CIs.

Given there was no measure of CWP as the diet and lifestyle information was captured, a sensitivity analysis was conducted on individuals who were free of low back pain at 33 years of age. By nature of the definition, low back pain is a component of CWP; therefore, excluding individuals with low back pain would also exclude those with CWP. This provided a subset of individuals who did not have CWP at 33 years of age when diet and lifestyle information was collected.

Diet and lifestyle may not be stable over time. Therefore, a weighted kappa statistic was used to assess changes in diet (fruit and vegetable, fatty food and chips intake) and physical activity level from 33 to 42 years of age. Values of weighted kappa $\left(\mathrm{k}_{\mathrm{w}}\right)$ between 0.61 and 0.80 indicate good agreement, between 0.41 and 0.60 moderate agreement, 0.21 and 0.40 fair agreement, and less than 0.21 poor agreement (23). Diet stability from 33 to 42 years of age was also classified into unchanged, improved or poorer. The percentage of individuals who moved up or down by more than one classification level was calculated.

Ethics approval for the follow-up at 45 years of age was obtained from the South East (United Kingdom) Multi-Centre Research Ethics Committee (reference 01/1/44).

\section{RESULTS}

Of the 8572 participants who completed the pain questionnaires at 45 years of age, 1056 (12\%) had CWP, 3517 (41\%) had regional pain and $3999(47 \%)$ had no pain. Slightly more women than men reported CWP (13\% versus $12 \%$ ). Women with CWP had increased odds of having rarely consumed fruit and vegetables at 33 years of age compared with women reporting no pain (OR 2.0 [95\% CI 1.3 to 3.1]) (Table 1). They also had greater odds of having consumed high levels of fatty food (OR 1.7 [95\% CI 1.1 to 2.7]) and chips (OR 1.5 [95\% CI 1.0 to 2.4]). Although they were attenuated, these relationships remained after adjustment for marital status and social class, for rare fruit and vegetable consumption (OR 1.5 [95\% CI 0.9 to 2.5]) and for high consumption of fatty foods (OR 1.3 [95\% CI 0.8 to 2.2]).

Compared with individuals with no pain, a higher percentage of both women and men reporting CWP had previously unhealthy 
lifestyles (eg, smoking and high BMI) (Tables 1 and 2). Women with CWP had higher odds of having been unemployed (adjusted OR 1.4 [95\% CI 1.1 to 1.8]), exposed to higher physical exertion at work (adjusted OR 1.6 [95\% CI 1.2 to 2.2]), being a past (adjusted OR 1.4 [95\% CI 1.0 to 1.8]) or current smoker (adjusted OR 1.3 [95\% CI 1.0 to 1.7]), and being overweight (adjusted OR 1.5 [95\% CI 1.2 to 1.9]) or obese (adjusted OR 1.8 [95\% CI 1.3 to 2.5]) (Table 1). Similar results were noted in men. In particular, men with CWP at 45 years of age were nearly three times more likely to have been unemployed 12 years previously (adjusted OR 3.1 [95\% CI 2.1 to 4.7]) (Table 2). A sensitivity analysis on a subset of individuals who were free of low back pain at 33 years of age $(n=4923)$ did not affect the findings (results not shown).

\section{Diet and lifestyle stability}

The dietary differences noted for persons with CWP could only have had an effect on the risk of cancer and/or CVD if their diet was relatively stable. Between 33 and 42 years of age, women and men with CWP reported moderate stability in fruit and vegetable consumption (women $\mathrm{k}_{\mathrm{w}}=0.43$; men $\mathrm{k}_{\mathrm{w}}=0.45$ ) and in chips consumption (women and men $k_{w}=0.57$ ) (Table 3 ). Fatty food consumption was less stable over time (women $\mathrm{k}_{\mathrm{w}}=0.35$; men $\mathrm{k}_{\mathrm{w}}=0.30$ ). Overall, approximately one-third of women and men increased their fatty food consumption between 33 and 42 years of age. Women with CWP (13\%) were more likely to have large changes in fruit/vegetable consumption (eg, from high to low/rare) between 33 and 42 years of age compared with women with no pain $(8.9 \%)$, but the same was not true for men $(9.6 \%$ versus $9.6 \%$ ). Women were more likely than men to change their physical activity level over time $\left(\mathrm{k}_{\mathrm{w}}=0.15\right.$ versus $\left.\mathrm{k}_{\mathrm{w}}=0.23\right)$; however, both reported significant changes in physical activity level between 33 and 42 years of age $\left(k_{w}=0.19\right)$. Approximately $30 \%$ of both men and women increased their physical activity level, while approximately one-third decreased their level. Similar decreases in physical activity were noted in people with and without CWP.

\section{Nonresponse bias}

Compared with responders, nonresponders to the pain questionnaire at 45 years of age were more likely to have the following characteristics at 33 years of age: lower fruit and vegetable consumption, higher fatty food and chips consumption, lower Register General's social classification of occupation, greater physical effort at work and higher BMI; and they were more likely to be smokers, unemployed and not married. In men, $12 \%$ of both responders and nonresponders reported rare fruit and vegetable consumption and $16 \%$ of both groups reported high fatty food consumption. Female nonresponders were slightly more likely to have had higher fatty food ( $7.3 \%$ versus $5.0 \%)$ and rare fruit and vegetable consumption $(5.2 \%$ versus $4.6 \%$ ) compared with responders.

\section{DISCUSSION}

The overall prevalence of pain was 53\% (CWP 12\%, regional pain $41 \%)$, which is within the wide range of estimates in the general population $(24,25)$. The present study was the first to examine whether persons with CWP may have past diet and lifestyle characteristics that predisposed them to other chronic diseases - primarily cancer and CVD. We found that 45-year-old women with CWP reported a poorer diet (low fruit/vegetable and high fatty food consumption) 12 years previously relative to 45 -year-old women who were pain free. The relationship between pain and diet was attenuated after controlling for socioeconomic status. However, this is to be expected because people from low socioeconomic backgrounds tend to have poorer diets, and diet can be considered a marker of socioeconomic status (26). We also found that diet was relatively stable over 33 to 42 years of age, with the exception of women with CWP, whose diet was more likely to deteriorate. Therefore, compared with women with no pain, not only were women with CWP at 45 years of age more likely to have reported poorer diets at 33 years of age, they were also more likely to have reported an even poorer diet at 42 years of age. The poor dietary patterns found in women with CWP are consistent with an increased risk
TABLE 1

Unadjusted and adjusted ORs and $95 \% \mathrm{Cls}$ of chronic widespread pain (CWP) in women 45 years of age with respect to diet/lifestyle factors at 33 years of age $(n=4367)$

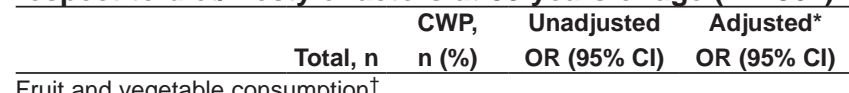

Fruit and vegetable consumption ${ }^{\dagger}$

Medium 1594

Low 1183

$111(22)$

$187(38)$

1

1

Rare

188

$165(33)$

$1.1(0.8-1.4) \quad 1.0(0.7-1.3)$

Fatty food consumption ${ }^{\ddagger}$

Rarely

Low

Medium

811

$33(6.7) \quad 2.0(1.3-3.1) \quad 1.5(0.9-2.5)$

$1.4(1.1-1.9) \quad 1.3(1.0-1.8)$

High

Chips consumption ${ }^{\ddagger}$

Rarely

Low

Medium

1872

$101(20)$

$218(44)$

1082

140 (28)

1

1

$0.9(0.7-1.2) \quad 0.9(0.7-1.3)$

$\quad 1.1(0.8-1.4) \quad 0.9(0.6-1.2)$

202

$36(7.3)$

$1.7(1.1-2.7) \quad 1.3(0.8-2.2)$

High

Alcohol consumption $\S$

Never

Rarely

Low

Medium

High

Physical activity"

High

Medium

Low

Rarely

Paid employment**

Yes

No

390

50 (10)

$1649186(38)$

1

1

$210(42)$

$0.9(0.7-1.3) \quad 1.0(0.7-1.4)$

$1.1(0.8-1.6) \quad 1.0(0.6-1.4)$

288

50 (10)

$1.5(1.0-2.4) \quad 1.1(0.7-1.9)$

Physical exertion at work ${ }^{\dagger}$

No

Yes

Smoking

Never

Past

Current

216
881

43 (8.7)

1

(1)

1

948

148 (30)

$0.9(0.6-1.3) \quad 0.8(0.5-1.3)$

$102(21) \quad 0.5(0.3-0.7) \quad 0.5(0.3-0.8)$

1635

177 (36)

$0.5(0.3-0.7) \quad 0.5(0.3-0.8)$

$26(5.2)$

$0.4(0.2-0.7)$

$0.5(0.3-0.8)$

Body mass index, $\mathrm{kg} / \mathrm{m}^{2}$

$<25$

25-29.9

1048

$150(30)$

816

81 (16)

94 (19)

169 (34)

1

$0.7(0.5-0.9) \quad 0.8(0.6-1.1)$

$0.7(0.5-0.9) \quad 0.7(0.5-0.9)$

$1.0(0.8-1.3) \quad 0.9(0.7-1.2)$

$\geq 30$

2787

315 (63)

1

1

1181

182 (37)

$1.4(1.2-1.7) \quad 1.4(1.1-1.8)$

Marital status

Single/never

Married (first marriage) 5574

Other

3299

$394(80)$

101 (20)

1

1

$1.6(1.2-2.1) \quad 1.6(1.2-2.2)$

Social class

Professional

Manager/technical

Skilled nonmanual

Skilled manual

Partly skilled

Unskilled

2029

$213(43)$

$104(21)$

1

$1.4(1.1-1.8) \quad 1.4(1.0-1.8)$

1184

$176(36)$

$1.7(1.4-2.1)$

$1.3(1.0-1.7)$

Other/unknown

$2585 \quad 280(57)$

$133(27)$

1

1

77 (16)

$1.5(1.2-1.9) \quad 1.5(1.2-1.9)$

$2.2(1.6-2.9) \quad 1.8(1.3-2.5)$

64 (13)

$300(62)$

1

$1.0(0.7-1.3) \quad 0.9(0.6-1.2)$

$122(25) \quad 1.4(1.0-2.0) \quad 1.2(0.8-1.7)$ (or both) >1 per day, medium frequency: fruit or vegetables (or both) 1 per day, low frequency: fruit and vegetables 1-6 days per week, rarely: fruit and vegetables <1 day per week; ${ }^{\ddagger}$ Rarely: occasionally or never, low frequency: <1 day per week, medium frequency: 1-2 days per week, high frequency: $\geq 1$ per day; $\S$ Never: not in past 12 months, rarely: $\leq 1$ time per month, low frequency: 2-4 times per month, medium frequency: 2-3 times per week, high frequency: $\geq 4$ times per week; "High frequency: 4-7 days per week, medium frequency: 2-3 days per week, low frequency: 1 day per week, rarely: $\leq 3$ days per month; **Yes: full/part time or self employed; no: unemployed, in education, sick, disabled, home or other; ${ }^{+\dagger}$ No: some, a little, no or not working; yes: a lot; ${ }^{\ddagger}$ Other: remarried (second or above), legally separated, divorced or widowed 


\begin{tabular}{|c|c|c|c|c|}
\hline & Total, $\mathbf{n}$ & $\begin{array}{l}\text { CWP, } \\
\text { n (\%) }\end{array}$ & $\begin{array}{l}\text { Unadjusted } \\
\text { OR }(95 \% \mathrm{Cl}) \\
\end{array}$ & $\begin{array}{c}\text { Adjusted }^{*} \\
\text { OR }(95 \% \mathrm{Cl})\end{array}$ \\
\hline \multicolumn{5}{|c|}{ Fruit and vegetable consumption $^{\dagger}$} \\
\hline High & 423 & $51(12)$ & 1 & 1 \\
\hline Medium & 1161 & $143(34)$ & $1.0(0.7-1.4)$ & $1.0(0.7-1.5)$ \\
\hline Low & 1655 & $182(43)$ & $0.9(0.6-1.2)$ & $0.8(0.6-1.2)$ \\
\hline Rarely & 445 & $51(12)$ & $1.0(0.6-1.5)$ & $0.8(0.5-1.3)$ \\
\hline \multicolumn{5}{|l|}{ Fatty food consumption ${ }^{\ddagger}$} \\
\hline Rarely & 364 & $43(10)$ & 1 & 1 \\
\hline Low & 1315 & $134(31)$ & $0.9(0.6-1.3)$ & $1.0(0.7-1.5)$ \\
\hline Medium & 1431 & $178(42)$ & $1.1(0.8-1.6)$ & $1.1(0.7-1.7)$ \\
\hline High & 572 & $72(17)$ & $1.1(0.7-1.6)$ & $1.1(0.6-1.7)$ \\
\hline \multicolumn{5}{|l|}{ Chips consumption ${ }^{\ddagger}$} \\
\hline Rarely & 138 & $18(4.2)$ & 1 & 1 \\
\hline Low & 1033 & $111(26)$ & $0.8(0.5-1.4)$ & $1.0(0.5-1.8)$ \\
\hline Medium & 1871 & 217 (51) & $0.9(0.5-1.4)$ & $0.8(0.4-1.5)$ \\
\hline High & 638 & $80(19)$ & $1.0(0.6-1.8)$ & $0.8(0.4-1.6)$ \\
\hline \multicolumn{5}{|l|}{ Alcohol consumption $\S$} \\
\hline Never & 105 & $20(4.7)$ & 1 & 1 \\
\hline Rarely & 343 & $42(9.8)$ & $0.6(0.3-1.2)$ & $0.6(0.3-1.3)$ \\
\hline Low & 571 & $58(14)$ & $0.5(0.3-1.0)$ & $0.6(0.3-1.2)$ \\
\hline Medium & 2030 & $237(56)$ & $0.6(0.3-1.0)$ & $0.8(0.4-1.5)$ \\
\hline High & 634 & $70(16)$ & $0.5(0.3-1.0)$ & $0.8(0.4-1.5)$ \\
\hline \multicolumn{5}{|l|}{ Physical activity } \\
\hline High & 862 & $96(23)$ & 1 & 1 \\
\hline Medium & 895 & $85(20)$ & $0.8(0.6-1.2)$ & $0.9(0.7-1.4)$ \\
\hline Low & 797 & $96(23)$ & $1.0(0.7-1.4)$ & $1.1(0.8-1.5)$ \\
\hline Rarely & 1124 & $149(35)$ & $1.2(0.9-1.6)$ & $1.1(0.8-1.5)$ \\
\hline \multicolumn{5}{|l|}{ Paid employment** } \\
\hline Yes & 3414 & $363(85)$ & 1 & 1 \\
\hline No & 267 & $64(15)$ & $2.8(2.0-3.9)$ & $3.1(2.1-4.7)$ \\
\hline \multicolumn{5}{|l|}{ Physical exertion at work ${ }^{\dagger \dagger}$} \\
\hline No & 2552 & $256(60)$ & 1 & 1 \\
\hline Yes & 1127 & $179(40)$ & $1.7(1.4-2.1)$ & $1.5(1.2-2.0)$ \\
\hline \multicolumn{5}{|l|}{ Smoking } \\
\hline Never & 1841 & $182(43)$ & 1 & 1 \\
\hline Past & 722 & $93(22)$ & $1.4(1.1-2.0)$ & $1.4(1.0-1.9)$ \\
\hline Current & 1104 & $151(35)$ & $1.7(1.3-2.1)$ & $1.3(1.0-1.7)$ \\
\hline \multicolumn{5}{|c|}{ Body mass index, $\mathrm{kg} / \mathrm{m}^{2}$} \\
\hline$<25$ & 1804 & $174(42)$ & 1 & 1 \\
\hline $25-29.9$ & 1462 & $183(44)$ & $1.3(1.1-1.7)$ & $1.3(1.0-1.6)$ \\
\hline$\geq 30$ & 366 & $62(15)$ & $2.0(1.4-2.7)$ & $1.9(1.3-2.7)$ \\
\hline \multicolumn{5}{|l|}{ Marital status ${ }^{\ddagger \ddagger}$} \\
\hline Single/never & 721 & $68(16)$ & 1 & 1 \\
\hline Married (first marriage) & 2360 & $270(65)$ & $1.3(1.0-1.8)$ & $1.6(1.1-2.2)$ \\
\hline Other & 497 & $77(19)$ & $1.8(1.3-2.7)$ & $2.0(1.3-2.9)$ \\
\hline \multicolumn{5}{|l|}{ Social class } \\
\hline Professional & 281 & $25(6.1)$ & 1 & 1 \\
\hline Manager/technical & 1204 & $97(24)$ & $1.0(0.6-1.6)$ & $1.0(0.6-1.6)$ \\
\hline Skilled nonmanual & 384 & $33(8.0)$ & $1.1(0.6-2.0)$ & $0.9(0.5-1.6)$ \\
\hline Skilled manual & 1134 & $164(40)$ & $2.1(1.3-3.3)$ & $1.5(0.9-2.5)$ \\
\hline Partly skilled & 392 & $62(15)$ & $2.7(1.6-4.5)$ & $1.8(1.0-3.2)$ \\
\hline Unskilled & 104 & $18(4.4)$ & $2.9(1.4-5.9)$ & $1.7(0.8-3.7)$ \\
\hline Other/unknown & 112 & $12(2.9)$ & $1.5(0.7-3.1)$ & $1.2(0.5-2.8)$ \\
\hline
\end{tabular}

${ }^{*}$ All variables included in adjusted model; ${ }^{\dagger}$ High frequency: fruit or vegetables (or both) >1 per day, medium frequency: fruit or vegetables (or both) 1 per day, low frequency: fruit and vegetables 1-6 days per week, rarely: fruit and vegetables <1 day per week; ${ }^{\ddagger}$ Rarely: occasionally or never, low frequency: $<1$ day per week, medium frequency: 1-2 days per week, high frequency: $\geq 1$ per day;

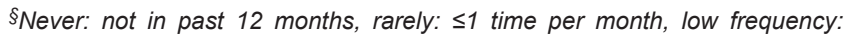
2-4 times per month, medium frequency: 2-3 times per week, high frequency: $\geq 4$ times per week; "High frequency: 4-7 days per week, medium frequency: 2-3 days per week, low frequency: 1 day per week, rarely: $\leq 3$ days per month; **Yes: full/part time or self employed; no: unemployed, in education, sick, disabled, home or other; ${ }^{\dagger+}$ No: some, a little, no or not working; yes: a lot; ¥¥Other: remarried (second or above), legally separated, divorced or widowed
TABLE 3

Diet stability in women and men at 33 and 42 years of age

\begin{tabular}{|c|c|c|c|c|}
\hline & \multicolumn{2}{|c|}{ Women } & \multicolumn{2}{|c|}{ Men } \\
\hline & $\begin{array}{l}\text { No pain } \\
(n=1883)\end{array}$ & $\begin{array}{c}\text { CWP } \\
(n=481)\end{array}$ & $\begin{array}{l}\text { No pain } \\
(n=1669)\end{array}$ & $\begin{array}{c}\text { CWP } \\
(n=431)\end{array}$ \\
\hline \multicolumn{5}{|l|}{ Fruit/vegetables, $\%$} \\
\hline Unchanged diet & 46 & 43 & 46 & 44 \\
\hline Improved their diet & 30 & 27 & 22 & 28 \\
\hline Poorer diet & 25 & 30 & 32 & 28 \\
\hline Changed by $>1$ category & 8.9 & 13 & 9.6 & 9.6 \\
\hline Weighted kappa* & 0.49 & 0.43 & 0.49 & 0.45 \\
\hline \multicolumn{5}{|l|}{ Fatty foods, $\%$} \\
\hline Unchanged diet & 38 & 39 & 38 & 35 \\
\hline Improved their diet & 26 & 27 & 32 & 32 \\
\hline Poorer diet & 36 & 34 & 30 & 33 \\
\hline Changed by $>1$ category & 16 & 16 & 17 & 19 \\
\hline Weighted kappa & 0.36 & 0.35 & 0.35 & 0.30 \\
\hline \multicolumn{5}{|l|}{ Chips, \% } \\
\hline Unchanged diet & 53 & 54 & 51 & 52 \\
\hline Improved their diet & 29 & 29 & 16 & 17 \\
\hline Poorer diet & 18 & 17 & 32 & 31 \\
\hline Changed by $>1$ category & 5.4 & 6.4 & 5.3 & 6.6 \\
\hline Weighted kappa & 0.58 & 0.57 & 0.56 & 0.57 \\
\hline
\end{tabular}

${ }^{*} P<0.05$. CWP Chronic widespread pain

of cancer and CVD, which supports our hypothesis that the relationship between CWP, and cancer and CVD may be partially explained by diet. However, in men, there was no association between diet and CWP. We also found elevated BMI and past and current smoking to be associated with CWP in both men and women. Both are consistent with an increased risk of cancer and CVD. In contrast, there was no association between physical activity and CWP in men and women; however, a physically demanding job was associated with CWP for both sexes. While a physically demanding job may also reflect socioeconomic status, these associations remained after adjusting for social class.

It is surprising that we demonstrated differences in past diet for women but not men. Previous epidemiological studies of CWP that focused on past health, mood, emotional factors and illness behaviour have not reported differences in their influence between men and women. However, the men in the present study had less healthy diets than women overall, which is consistent with data reported in the literature (22). The narrower spread of intakes of fruit and vegetables and fatty foods observed in men, compared with women, could have limited the ability to detect a link between CWP and diet in men (22). However, another explanation for the lack of association is simply that poor diet is not a contributory factor to CWP in men.

There is a paucity of information on diet and CWP; however, evidence is beginning to emerge that supports a link between diet and pain. Low levels of 25-hydroxyvitamin D have been associated with reported musculoskeletal pain (12) and, specifically in South Asian populations, related to reported CWP $(13,14)$. However, previous analyses of the current cohort have suggested that vitamin D status is not a major determinant of CWP, although interestingly, all effects were found in women (27). Dietary markers, including low fruit and vegetable consumption, have been identified for inflammatory arthritis (11); however, the proportion of patients with CWP who have an identified physiological cause for their symptoms is very low (28). BMI is also a potential explanatory factor in the relationship between diet and CWP because persons with poorer diets are more likely to be overweight. A dose-response relationship between BMI and both pain intensity and number of pain sites has been reported (15). Persons with CWP have been found more likely to be overweight (16). Our findings support previous findings on the relationship between smoking and pain (10), and BMI and pain (29). Both relationships were independent of diet. 
There is little evidence regarding the relationship between CWP and physical activity. Previous epidemiological studies have demonstrated that physical fitness reduces the risk of musculoskeletal pain $(9,30)$ and that physical fitness is associated with a greater likelihood of recovery among those with an episode of musculoskeletal pain such as low back pain (31). There is also evidence of a U-shaped distribution between physical activity and low back pain, which supports the relationship found in the present study (32). Persons with CWP were more likely to report both very low and very high past levels of physical activity in the crude analysis. After controlling for other factors (eg, physical exertion at work and social class), physical activity level was no longer a significant independent predictor of CWP; however, the trend toward higher levels of CWP in respondents reporting past low or high physical activity remained. The link between physical activity, CWP and cancer could operate in at least two ways. First, persons with low levels of physical activity could be at high risk of developing CWP, and once symptoms develop, physical activity remains low. Alternatively, persons participating in normal to high levels of activity reduce their activity level after developing CWP because of pain. The impact of high levels of physical activity (eg, damage to joints, and torn muscles) may also lead to CWP in at least two ways: directly - due to injury; or indirectly - whereby injury results in reduced physical activity and thereby increases the risk of CWP from inactivity.

There are several methodological considerations for interpreting the data from the present study. First, only approximately one-half of the children who were recruited in 1958 participated as adults in the latest follow-up. A previous examination of bias in the sample reported that the remaining participants were broadly representative of the total surviving 1958 cohort in terms of key characteristics (33). However, the socioeconomically disadvantaged group was more likely to be under-represented than other groups in the 45-year-old sample. Under-representation was also present for obesity and smoking characteristics. Given that individuals with CWP were more likely to have these characteristics, the prevalence of CWP at 45 years of age is likely higher than the $12 \%$ to $13 \%$ reported in our study. Further details about loss and representativeness of the 1958 British Birth Cohort in the 45-year-old follow-up are published elsewhere (33). Our analysis of nonresponse to the pain questionnaires suggests that bias due to nonresponse was minimal. It is also unlikely that the relationship between diet and lifestyle, and CWP differs for responders and nonresponders.

Second, nonparticipation bias could only have been an explanation for the relationship between CWP and diet if women with CWP

\section{REFERENCES}

1. Macfarlane GJ, McBeth J, Silman AJ. Widespread body pain and mortality: Prospective population based study. BMJ 2001;323:662-5.

2. McBeth J, Silman AJ, Macfarlane GJ. Association of widespread body pain with an increased risk of cancer and reduced cancer survival: A prospective, population-based study. Arthritis Rheum 2003;48:1686-92.

3. McBeth J, Symmons DP, Silman AJ, et al. Musculoskeletal pain is associated with a long-term increased risk of cancer and cardiovascular related mortality. Rheumatology 2009;48:74-7.

4. Hubert HB, Feinleib M, McNamara PM, Castelli WP. Obesity as an independent risk factor for cardiovascular disease: A 26-year follow-up of participants in the Framingham heart study. Circulation 1983;67:968-77.

5. International Agency for Research on Cancer. Handbook of Cancer Prevention: Weight Control and Physical Activity, volume 6. Lyon: International Agency for Research on Cancer Press, 2002.

6. Khot UN, Khot MB, Bajzer CT, et al. Prevalence of conventional risk factors in patients with coronary heart disease. JAMA 2003;290:898-904.

7. Reeves GK, Pirie K, Beral V, et al. Cancer incidence and mortality in relation to body mass index in the million women study: Cohort study. BMJ 2007;335:1134.

8. Gandini S, Botteri E, Iodice S, et al. Tobacco smoking and cancer: A meta-analysis. Int J Cancer 2008;122:155-64. were $10 \%$ to $15 \%$ less likely to have attended the visit at 45 years of age if their diet 12 years previously had been of 'high quality' rather than 'low quality'. This seems unlikely. Third, the assessment of diet in the present study is relatively crude because it is based on intake of a few key foods - also, it is based on frequency rather than amount. In addition, frequency categories do not capture key dietary recommendations such as eating five fruits and vegetables per day. However, this method has been shown to be adequate for ranking participants with respect to high to low dietary intake. It is likely that the relationship would have been stronger if more comprehensive measures of diet had been used. The information on diet was collected 12 years and three years before the pain report and the data demonstrated, in accordance with previous observations, that the dietary patterns were relatively stable (19). A further methodological issue is the relatively crude measure of physical activity. It is possible that these measures are not capturing differences between persons with and without CWP. A more important methodological consideration is that we do not know whether the women who reported CWP at 45 years of age already had CWP at the survey conducted at 33 years of age, and this may have affected their diet. However, we know from previous epidemiological studies that it is very unusual for adults to develop CWP in adulthood if they reported no pain in a previous survey, and we know that it is equally unusual for CWP to resolve completely (34). A sensitivity analysis restricted to those free of low back pain at 33 years of age - and, therefore, by definition, free of CWP - yielded findings that were similar to the main results. This suggests that poor diet precedes CWP instead of being a consequence of it.

In summary, the present study provided new insights into the relationship between diet and lifestyle, and CWP. We demonstrated that individuals with CWP, especially women, have diet and lifestyle risk factors that are also common in persons with cancer or CVD. We recommend that rheumatologists emphasize the importance of a healthy diet as part of their overall management of patients with CWP. Future research is required to examine why risk factors for cancer and CVD are more common in individuals with CWP.

FUNDING: This work was supported by the Medical Research Council, United Kingdom (Health of the Public initiative grant G0000934) (data collection). The University College London Institute of Child Health and Great Ormond Street Hospital receive a portion of funding from the Department of Health's National Institute for Health Research Biomedical Research Centres funding scheme.

9. Hildebrandt VH, Bongers PM, Dul J, van Dijk FJ, Kemper HC. The relationship between leisure time, physical activities and musculoskeletal symptoms and disability in worker populations. Int Arch Occup Environ Health 2000;73:507-18.

10. John U, Hanke M, Meyer C, Volzke H, Baumeister SE, Alte D. Tobacco smoking in relation to pain in a national general population survey. Prev Med 2006;43:477-81.

11. Pattison DJ, Silman AJ, Goodson NJ, et al. Vitamin C and the risk of developing inflammatory polyarthritis:

Prospective nested case-control study. Ann Rheum Dis 2004:63:843-7.

12. de Torrente de la Jara G, Pecoud A, Favrat B. Musculoskeletal pain in female asylum seekers and hypovitaminosis D3. BMJ 2004;329:156-7.

13. Helliwell PS, Ibrahim GH, Karim Z, Sokoll K, Johnson H. Unexplained musculoskeletal pain in people of South Asian ethnic group referred to a rheumatology clinic - relationship to biochemical osteomalacia, persistence over time and response to treatment with calcium and vitamin D. Clin Exp Rheumatol 2006;24:424-7.

14. Macfarlane GJ, Palmer B, Roy D, Afzal C, Silman AJ, O'Neill T. An excess of widespread pain among South Asians: Are low levels of vitamin D implicated? Ann Rheum Dis 2005;64:1217-9. 
15. Hitt HC, McMillen RC, Thornton-Neaves T, Koch K, Cosby AG. Comorbidity of obesity and pain in a general population: Results from the southern pain prevalence study. J Pain 2007;8:430-6.

16. Macfarlane GJ, Jones GT, Knekt P, et al. Is the report of widespread body pain associated with long-term increased mortality? Data from the mini-Finland health survey. Rheumatology 2007;46:805-7.

17. Power C, Elliott J. Cohort profile: 1958 British Birth Cohort (national child development study). Int J Epidemiol 2006;35:34-41.

18. Wolfe F, Smythe HA, Yunus MB, et al. The American College of Rheumatology 1990 criteria for the classification of fibromyalgia. Report of the multicenter criteria committee. Arthritis Rheum 1990;33:160-72.

19. Parsons TJ, Manor O, Power C. Changes in diet and physical activity in the 1990s in a large British sample (1958 birth cohort). Eur J Clin Nutr 2005;59:49-56.

20. Williams DA, Gendreau M, Hufford MR, Groner K, Gracely RH, Clauw DJ. Pain assessment in patients with fibromyalgia syndrome: A consideration of methods for clinical trials. Clin J Pain 2004:20:348-56.

21. Clauw DJ, Crofford LJ. Chronic widespread pain and fibromyalgia: What we know, and what we need to know. Baillieres Best Pract Res Clin Rheumatol 2003;17:685-701.

22. Hoare J, Henderson L, Bates CJ, et al. National diet and nutrition survey: Adults aged 19 to 64 . Volume 5: Summary report. London: TSO, 2004.

23. Landis JR, Koch GG. An application of hierarchical kappa-type statistics in the assessment of majority agreement among multiple observers. Biometrics 1977;33:363-74.

24. Elliott AM, Smith BH, Penny KI, Smith WC, Chambers WA. The epidemiology of chronic pain in the community. Lancet 1999;354:1248-52.
25. Tripp DA, VanDenKerkhof EG, McAlister M. Prevalence and determinants of pain and pain-related disability in urban and rural settings in southeastern Ontario. Pain Res Manage 2006;11:225-33.

26. Dowler E. Inequalities in diet and physical activity in Europe. Public Health Nutr 2001;4(2B):701-9.

27. Atherton K, Berry DJ, Parsons T, Macfarlane GJ, Power C, Hypponen E. Vitamin D and chronic widespread pain in a white middle-aged British population: Evidence from a cross-sectional population survey. Ann Rheum Dis 2008;68:817-22.

28. McBeth J, Chew-Graham C, Macfarlane GJ, Davies I, Jackson J, Creed F. The prevalence of "unexplained" chronic widespread pain in the general population: Results from the general practice symptoms study. Rheumatology 2008;47:ii192.

29. Palmer KT, Syddall H, Cooper C, Coggon D. Smoking and musculoskeletal disorders: Findings from a British national survey. Ann Rheum Dis 2003;62:33-6.

30. Van Den Heuvel SG, Heinrich J, Jans MP, Van Der Beek AJ, Bongers PM. The effect of physical activity in leisure time on neck and upper limb symptoms. Prev Med 2005;41:260-7.

31. Thomas E, Silman AJ, Croft PR, Papageorgiou AC, Jayson MIV, Macfarlane GJ. Predicting who develops chronic low back pain in primary care: A prospective study. Br Med J 1999;318:1662-7.

32. Heneweer H, Vanhees L, Picavet HS. Physical activity and low back pain: A U-shaped relation? Pain 2009;143:21-5.

33. Atherton K, Fuller E, Shepherd P, Strachan DP, Power C. Loss and representativeness in a biomedical survey at age 45 years: 1958 British Birth Cohort. J Epidemiol Community Health 2008;62:216-23.

34. Papageorgiou AC, Silman AJ, Macfarlane GJ. Chronic widespread pain in the population: A seven year follow up study. Ann Rheum Dis 2002;61:1071-4. 


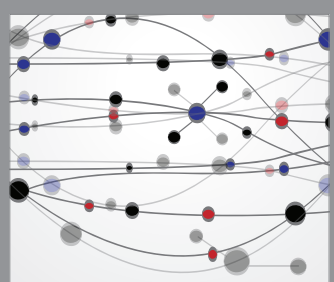

The Scientific World Journal
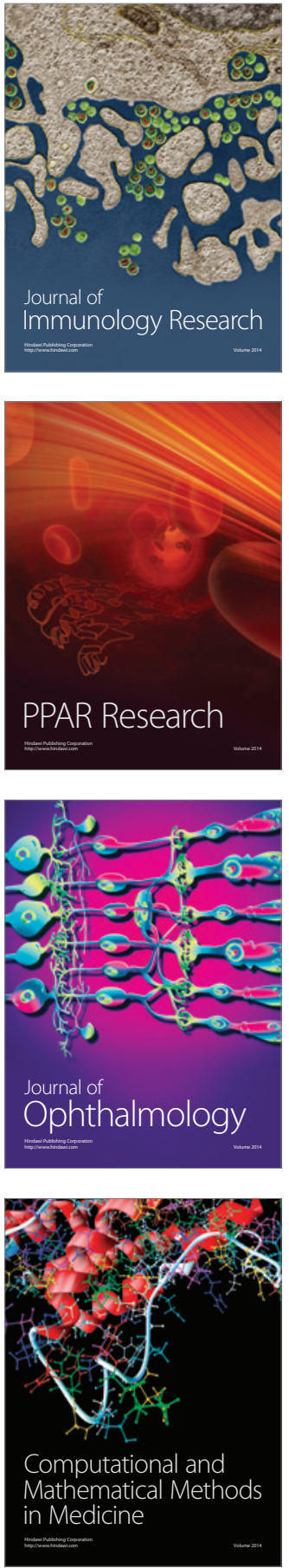

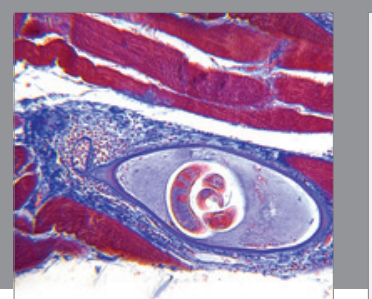

Gastroenterology Research and Practice

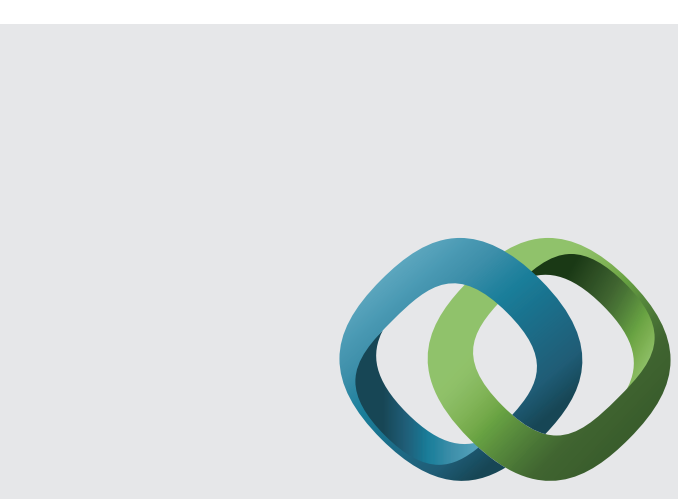

\section{Hindawi}

Submit your manuscripts at

http://www.hindawi.com
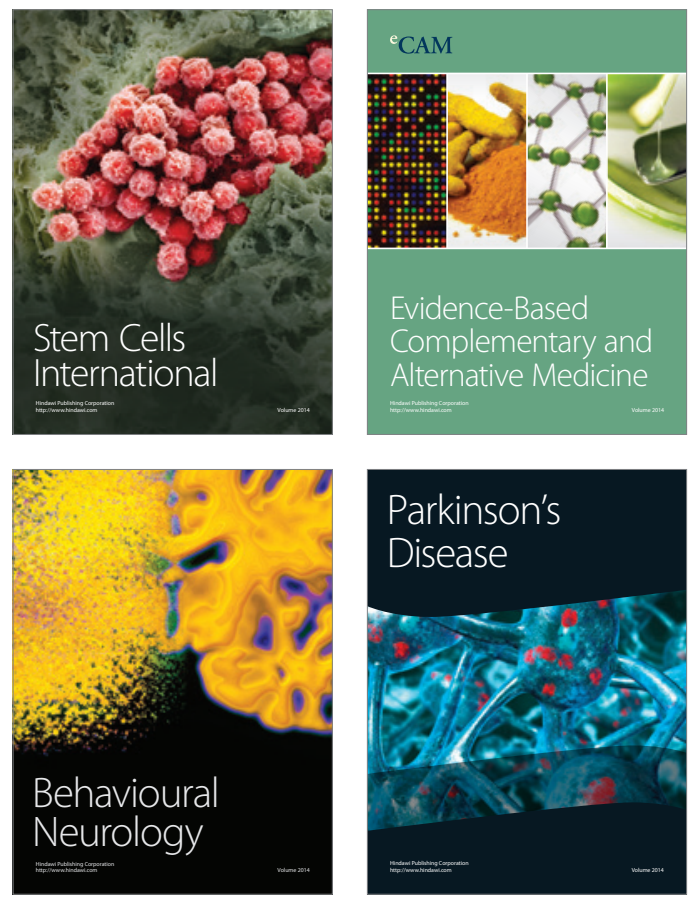
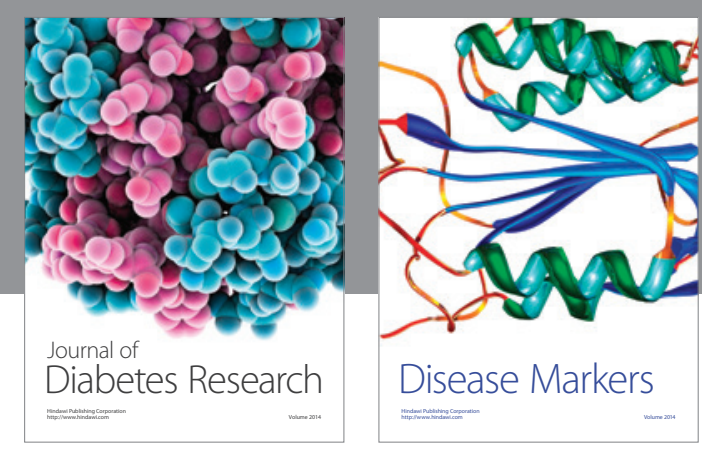

Disease Markers
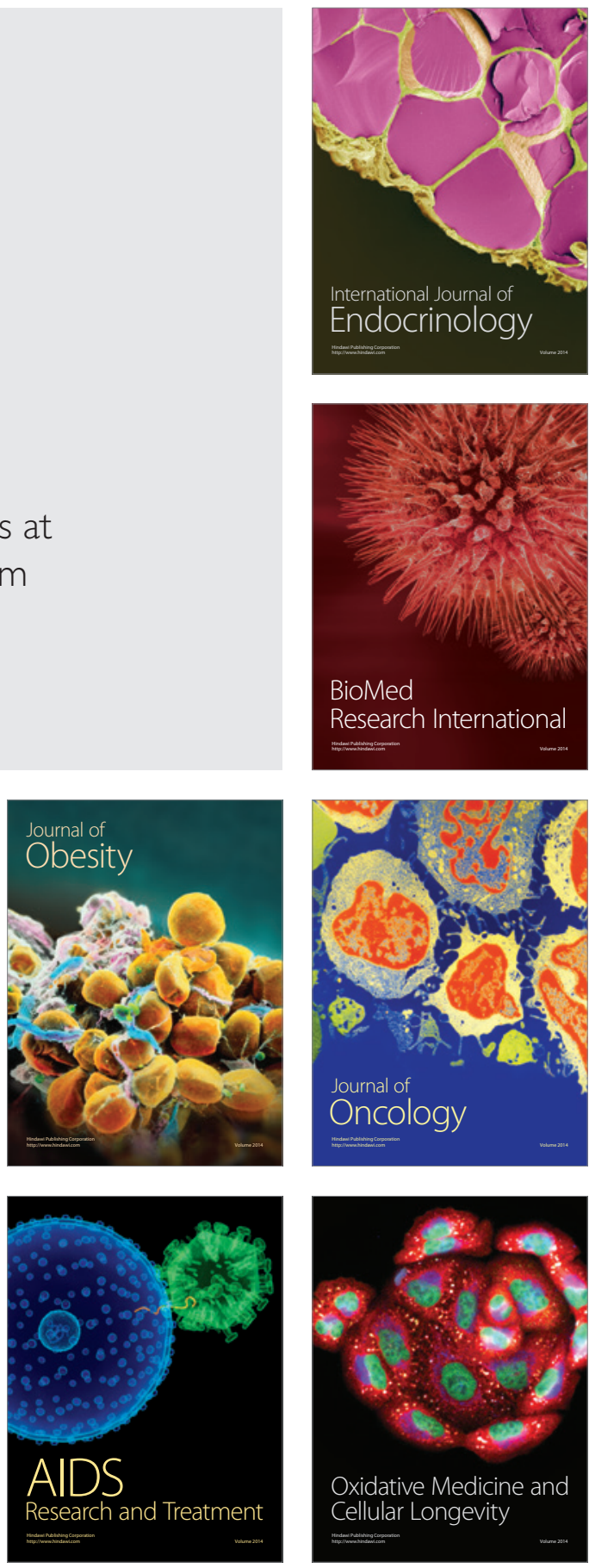